\title{
River Flow Prediction for Future Climate Using Long Series of Multi-Site Synthetic Data and MIKE SHE Model
}

\author{
Leszek Kuchar ${ }^{1, *}$, Slawomir Iwanski ${ }^{1}$, and Leszek Jelonek ${ }^{2}$ \\ ${ }^{1}$ Wroclaw University of Environmental and Life Sciences, Department of Mathematics, \\ 50357 Wroclaw, Poland \\ ${ }^{2}$ Institute of Meteorology and Water Management - Branch Wroclaw, 51618 Wroclaw, Poland
}

\begin{abstract}
A new simulation of daily flow for Kaczawa River, south-west Poland for extra long series of generated meteorological data (comparing to previous research) and selected climate change scenarios are presented. The Representative Concentration Pathways (RCPs) scenarios vs. SRES are introduced for simulations. The flow simulation in the river catchment is made using MIKE SHE hydrological model while the multisite data are generated by spatial weather generator SWGEN. Simulations are done for 2040 and 2060 while the simulations for the year 2000 are used as a background. The large number of new simulated series determined by the lead time, three climate change scenarios (RCP2.6 RCP4.5 and RCP6.0), and number of generated years (1000 for each case) is equal to 7000 for a single station. Finally, Pdf function for flow is presented as well probability of exceedance of maximum flow.
\end{abstract}

\section{Introduction}

The future climate change may have a significant impact on the forthcoming hydrology in the river catchment, runoff response, and predictions $[1,3,5,8,24,25,28,33]$. The daily flow simulation, particularly seasonal extremes for future climate conditions given by different scenarios are important for the Polish rivers for several reasons $[15,17,27]$. The paper presents an example of new simulation of seasonal flow for the relative small catchment of Kaczawa River a left side tributary of the Odra River (Southwest region of Poland) for selected climate change scenarios is presented. Above simulations extended study are compared to the earlier research $[15,16,17]$.

\section{Methods}

The idea of runoff simulation in the river catchment for future climate conditions given by different scenarios are presented in Figure 1 and the same philosophy comparing to earlier works is used $[15,16,17]$. This procedure combines a hydrological model, spatial

* Corresponding author: Leszek.Kuchar@gmail.com 
weather generator producing synthetic weather data and climate change scenarios $[12,17]$. Simulations give a knowledge for a decision support system.

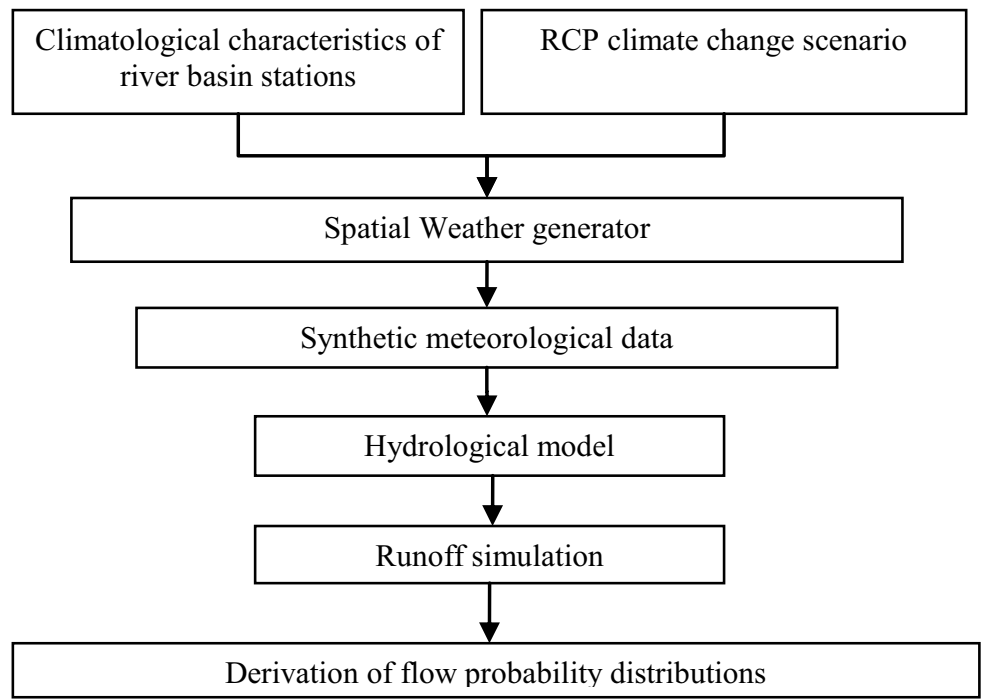

Fig. 1. Diagram of river flow simulation for future climate using synthetic meteorological data and climate change scenario.

\subsection{Climate change scenario selection}

Changes during the winter and summer season in different regions and scales of the country are symptomatic $[3,6,12,13,24,26]$. The impact of climate change according to the approved set of emission scenarios described in the IPCC Special Report on Emission Scenarios (SRES) [10], and A1B (most used SRES scenario) were used as typical for Poland. Particularly, scenarios given by GISS Model E, HadCM3 and GFDL R15 assuming doubling the $\mathrm{CO}_{2}$ concentration, which is expected for years 2050-2060 were applied. As the baseline conditions, year 2000 was chosen, according to reference period: 1990-2010. A new $5^{\text {th }}$ IPCC Rapport 2014 [11] changes a philosophy of SRES to a new set of scenarios, the Representative Concentration Pathways (RCPs) and implies them for the new climate simulations. The RCP includes time series of emissions and concentrations of full suite of GHG gases and aerosols and chemically active gases, as well as land use cover. Predictions for surface temperature for Poland are more adequate comparing to previous SRES scenarios, and therefore, new RCP scenarios (particularly RCP2.6, RCP4.5 and RCP6.0) are introduced for simulations.

However, the experience with new RCPs scenarios are much lower comparing to previous emissions scenarios SRES, the most Earth System Model simulations were performed with prescribed $\mathrm{CO} 2$ concentrations reaching $538 \mathrm{ppm}$ (RCP4.5), $670 \mathrm{ppm}$ (RCP6.0) to the year 2100. Including also $\mathrm{CH} 4$ and $\mathrm{N} 2 \mathrm{O}$ the combined $\mathrm{CO} 2$ equivalent concentration are $630 \mathrm{ppm}$ (RCP4.5), $800 \mathrm{ppm}$ (RCP6.0) [10, 11]. Therefore, in the simulations two main scenarios RCP4.5 and RCP6.0 (RCPs) similar to GISS Model E, HadCM3, GFDL R15 (previously used and based on SRES) and in addition RCP2.6 scenario as most probable for Poland are considered $[15,16,17]$. This is also a compromise between experience and recent knowledge for study on climate change impact on environment. 


\subsection{Synthetic weather data}

Spatial weather generator SWGEN is used as best downscaling method to produce nyears of synthetic data on potentially possible weather course, $\mathrm{k}$ stations, the given time horizon and scenario $[2,4,7,12,19,32]$. The year 2000 as the background of the potential changes in catchments flow is used together with 1000 years of synthetic data.

The SWGEN model generates precipitation by means of the first-order Markov chain to determine the occurrence of wet/dry days, and then for the amount of rainfall multidimensional two-parameter gamma distribution $[12,17]$ :

$$
\left(\Gamma_{\mathrm{m}}\left(\alpha_{1}, \beta_{1}\right), \ldots, \Gamma_{\mathrm{m}}\left(\alpha_{\mathrm{k}}, \beta_{\mathrm{k}}\right)\right)
$$

where $m$ is the number of months $(\mathrm{m}=1, \ldots, 12)$ and $k$ is the number of locations, while daily values of solar radiation $(\mathrm{SR})$, temperature maximum $\left(\mathrm{T}_{\max }\right)$ and minimum $\left(\mathrm{T}_{\min }\right)$ are considered as a multidimensional time series $\operatorname{AR}(1)$ in the following form:

$$
\mathbf{X}_{\mathrm{t}}=\boldsymbol{\Phi}_{\mathrm{m}} \cdot \mathbf{X}_{\mathrm{t}-1}+\boldsymbol{\varepsilon}_{\mathrm{t}}
$$

where $\mathbf{X}_{\mathrm{t}}$ and $\mathbf{X}_{\mathrm{t}-1}$ are vectors $(\mathrm{m} \times 1)$ of normalized values for all three variables for day $t$ and $t-1, \varepsilon_{\mathrm{t}}$ is a vector $(\mathrm{m} \times 1)$ of independent random components normally distributed with vector of mean equal to zero and matrix of covariance $\boldsymbol{\Sigma}_{\mathrm{m}}$, and $\boldsymbol{\Phi}_{\mathrm{m}}($ for $\mathrm{m}=1, \ldots, 12)$ is a matrix of parameters $[12,15,17]$.

\subsection{Flow simulation with rainfall-runoff model}

In the next stage, generated data were applied to hydrological rainfall-runoff model MIKE SHE $[9,22]$ to simulate runoff for closing water-gauges. The catchment runoffs are evaluated with a different temporal step (one day, five days and ten days). The obtained outflows for various simulations are characterized by probability distribution functions. Three parameter gamma probability distribution is used as the best distribution fitting the monthly outflow, and Pareto pdf for daily maximum outflow within the year $[12,15,29$, 30].

\section{Study Area}

The above simulation scheme was applied for the Kaczawa basin that is one of the main left bank tributaries of the Odra River - the second biggest river in Poland. Daily data of solar radiation, maximum and minimum air temperature, and total precipitation of a 28-year data series (1981-2008) of meteorological network within or around the Kaczawa River catchment, were obtained for 16 stations of hydrological network from Institute of Meteorology and Water Management. In addition, daily data of flows from 6 closing watergauges (partial catchments) were collected. 


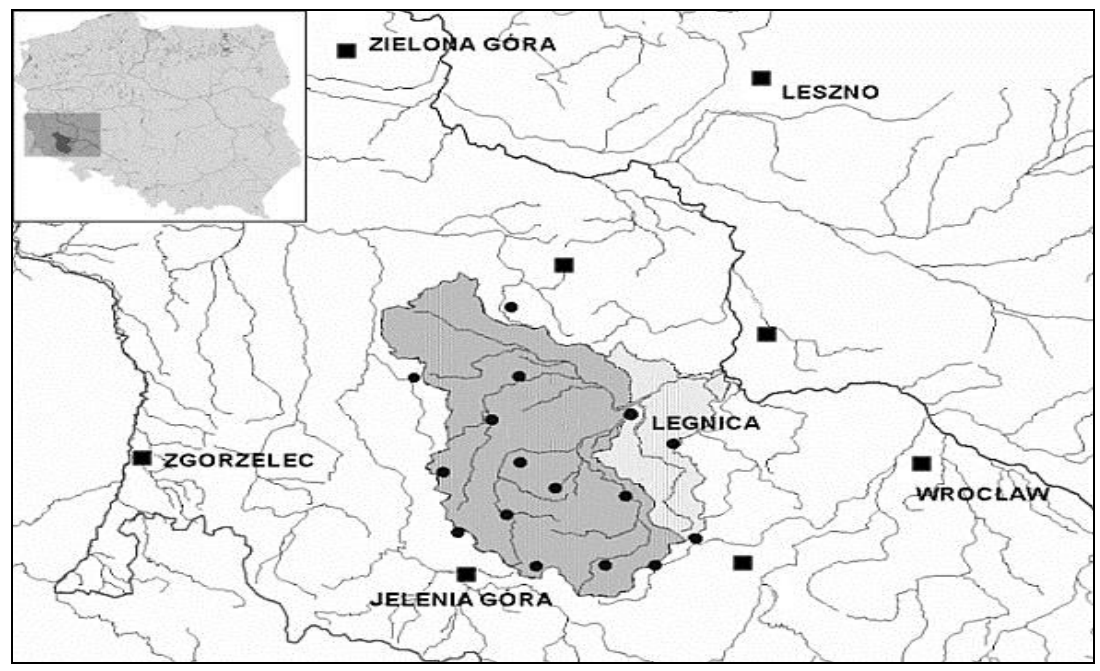

Fig. 2. The Kaczawa River catchment (left side tributary of the Odra River, area of $1807 \mathrm{~km}^{2}$, main sit: Legnica $\left.51^{\circ} 13^{\prime} \mathrm{N}, 16^{\circ} 14^{\prime} \mathrm{E}\right)$ with meteorological stations $(\bullet)$.

The basic climatological characteristics required by weather generator are computed $[12,18,31]$, and spatial correlations between variables and stations are added to the characteristics $[14,18]$.

Next, on the basis of information coming from climate change scenarios RCP2.6, RCP4.5 and RCP6.0, averaged and rescaled for years 2040, 2060 basic climatologic characteristics are modified. Then, spatial weather generator SWGEN is used to produce new long series of 1000 years (comparing to previous study [16]) of synthetic data for 16 stations, given time horizon and scenario. The year 2000 as the background of potential changes in river flow is used together with 1000 years of synthetic data. Next, generated data is applied to hydrological model MIKE SHE to simulate daily flows for closing watergauges. The flow is evaluated with different temporal step and characterized by Pdf functions.

\section{Results}

The simulations of daily runoff in the Kaczawa River catchment were done at discharge point in Piatnica. The number of simulations were determined by the time of horizon (2040, 2060 and 2000 as a background), three averaged climate change scenarios (RCP2.6, RCP4.5 and RCP6.0), and number of generated years (1000) for each case, with total of $7000(2 \times 3 \times 1000+1000)$ years. The MIKE SHE model computed for a given year, a daily flow at discharge point, and maximum value was chosen to estimate parameters of density function.

It means that the parameters of Pareto probability distribution were estimated for $7(2 \times 3+1)$ combinations, based on long series of 1000 computed runoff each.

As an example, Figure 3 presents probability of exceedance of maximum flow at discharge point at Piątnica for present conditions (year 2000) and two RCPs scenarios for 2040 and 2060 within July, while Figure 4 shows graphs probability of exceedance of maximum flow for 2040 and 2060 within the period May - August. 


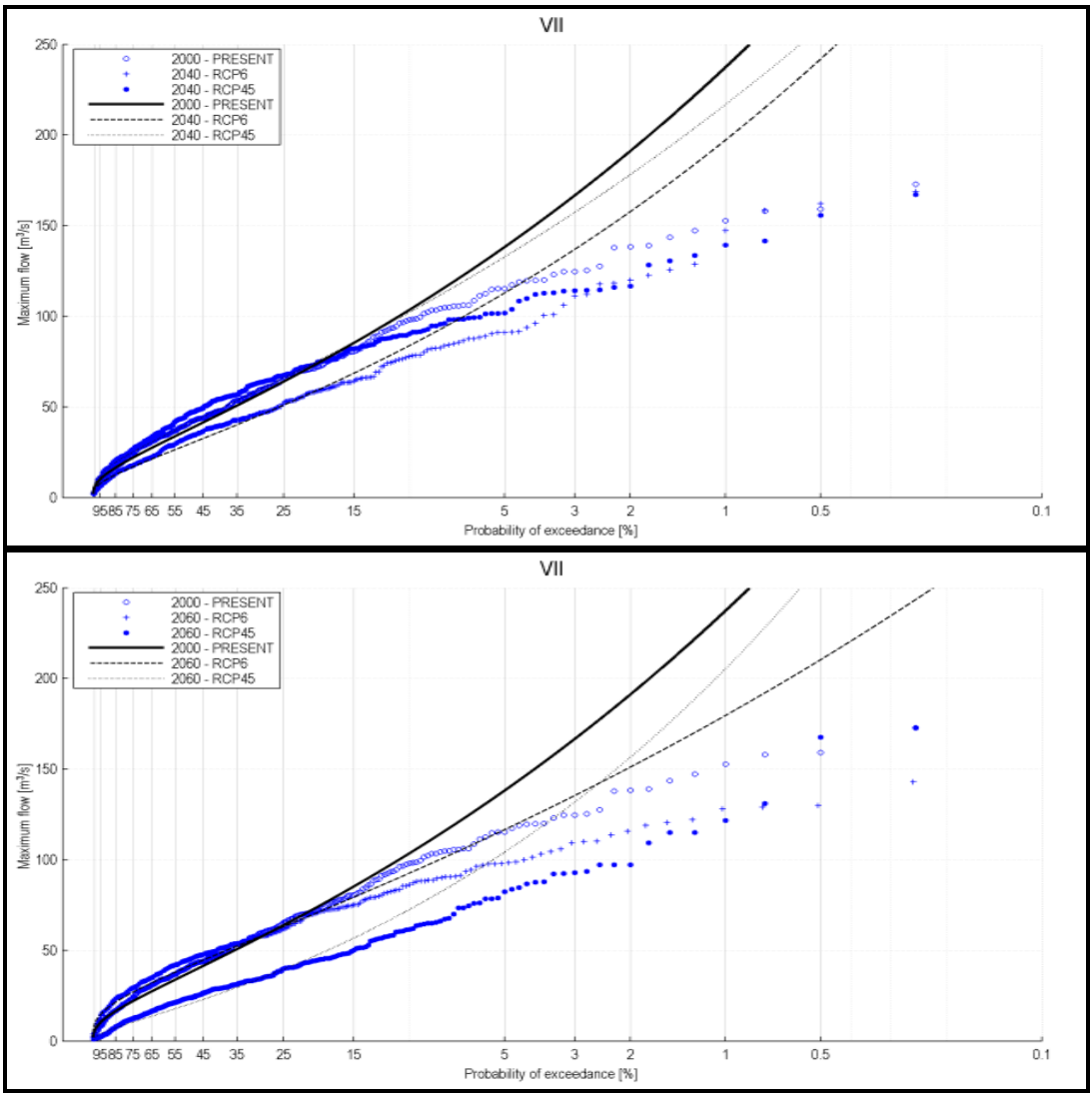

Fig. 3. Probability of exceedance of maximum flow within July at discharge point at Piatnica on the Kaczawa River, simulation for present conditions (year 2000) and two RCPs scenarios for 2040 and 2060.

The above simulations leads to the following remarks. The application of spatial weather generator SWGEN combined with hydrological rainfall-runoff model (MIKE SHE Ed. 2008) and climate change scenario, gives various possibilities to study changes in the river catchment coming up to $40-80$ years $[20,21,23]$. The probability distribution of the extreme river flow gives detailed information on the moment characteristics, confidence intervals and critical values. It is an important tool for a decision support system. In case of extreme daily flow in the Kaczawa River for considered periods, the catchment shows changes depending on the climate change scenario and time to lead.

New simulations with RCPs scenarios RCP4.5 and RCP6.0 give similar results as previously used SRES A1B scenarios from GISS Model E, HadCM3 and GFDL R15 [17]. Application of Pareto probability distribution shows some uncertainties for tail fitting, and suggests future studies, particularly nonparametric estimation.

However, simulations show a growing risk for $1 \%$ (and lower) probability of exceedance of maximum flow, RCP6.0 and sixty-year lead time. Above risk is higher for a longer period, for example during the period May - August than July.

Application of long generated weather series (1000 vs. 500 years) gives similar results as recently obtained [16]. 


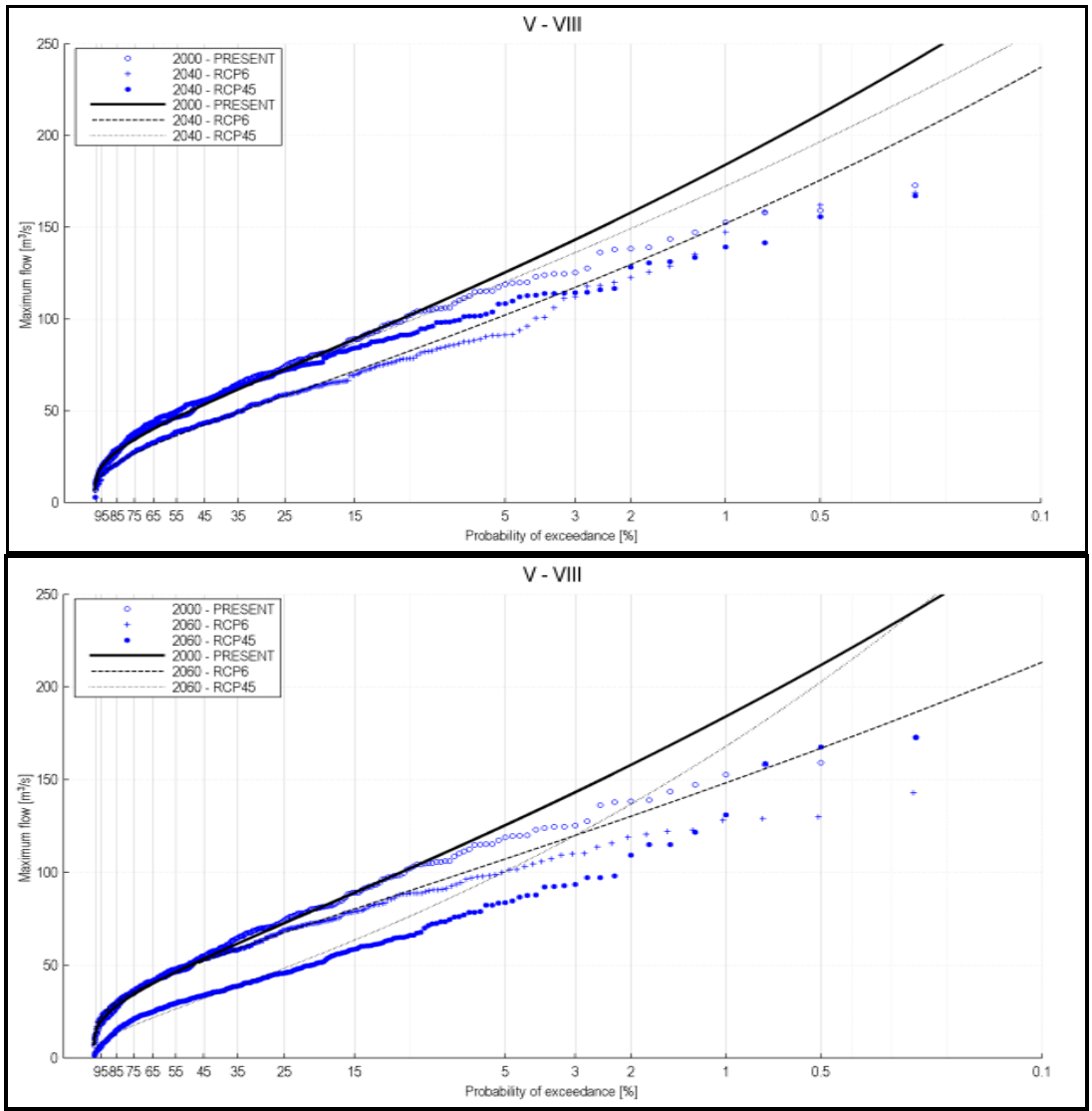

Fig. 4. Probability of exceedance of maximum flow during the period May - August at discharge point at Piatnica on the Kaczawa River, simulation for present conditions (year 2000) and two RCPs scenarios for 2040 and 2060.

\section{References}

1. T. Barnett, T. Malone, W. Pennell, D. Stammer, B. Semtner, W. Washington, Clim. Change, 62, 1 (2004)

2. J.J. Beersma, T.A. Buishand, Clim. Res. 25, 121 (2003)

3. S. Bergstrom, B. Carlsson, M. Gardelin, G. Lindstrom, A. Pettersson, M. Rummukainen, Clim. Res. 16, 101 (2001)

4. F. Brissette, M. Khalili, R. Leconte, J. Hydrol. 345, 121 (2007)

5. D.H. Burn, J. Hydrol. 160, 53 (1994)

6. H. Chen, C.Y. Xu, S. Guo, J. Hydrol. 434-435, 36 (2012)

7. J. Chen, F.P. Brissette, X.C. Zhang, Trans. ASABE, 57, 1375 (2014)

8. N.S. Christensen, A.W. Wood, N. Voisin, D.P. Lettenmaier, R.N. Palmer, Clim. Change, 62, 337 (2004)

9. D.N. Graham, M.B. Butts, Watershed Models (V.P. Singh, D.K. Frevert (Eds.), CRC Press, 2005)

10. IPCC-SRES-SPM WG III, Emissions Scenarios, Summary for Policy-makers, Special Report (IPCC, 2000)

11. IPCC WG I, II and III, Climate Change, Synthesis Report (IPCC, 2014) 
12. S. Iwanski, L. Kuchar, Acta Scientiarum Polonorum - Formatio Circumiectus, 2, 113 (2003)

13. R.N. Jones, F.H.S. Chiew, W.C. Boughton, L. Zhang, Adv. Water Resour. 29, 1419 (2006)

14. M. Khalili, R. Leconte, F. Brissette, J. Hydrometeorol. 8, 396 (2007)

15. L. Kuchar, S. Iwanski, L. Jelonek, W. Szalinska, Geografie, 119, 1 (2013)

16. L. Kuchar, S. Iwański, L. Jelonek, Water Resources, Hydraulics Facilities and Environment, The International Scientific-Practical Conference (Azersu, Baku, Azerbaijan, 2017)

17. L. Kuchar, S. Iwanski, L. Jelonek, W. Szalinska, Meteorol. Hydrol. Water Manag. 2-2, 49 (2014)

18. L. Kuchar, Math. Comp. Symul. 65, 69 (2004)

19. W.A. Landman, S.J. Mason, P.D. Tyson, W.J. Tennant, J. Hydrol. 252, 221 (2001)

20. L. Menzel, G. Burger, J. Hydrol. 267, 53 (2002)

21. W.S. Merritt, Y. Alila, M. Barton, B. Taylor, S. Cohen, D. Nielsen, J. Hydrol. 326, 79 (2006)

22. MIKE 11, A modelling system for Rivers and Channels, User Guide, (DHI Water and Environment, 2003)

23. M. Minville, F. Brissette, R. Leconte, J. Hydrol. 358, 70 (2008)

24. D.I. Müller-Wohlfeil, G. Bürger, W. Lahmer, Clim. Change, 47, 61 (2000)

25. C. Prudhomme, N. Reynard, S. Crooks, Hydrol. Process. 16, 1137 (2002)

26. J.R. Thompson, Hydrol. Res. 43, 507 (2012)

27. T. Tokarczyk, W. Szalinska, A. Tiukalo, J. Jelowicki, A. Chorazyczewski, Meteorol. Hydrol. Water Manag. 4-1, 65 (2016)

28. T. Vansteenkiste, M. Tavakoli, V. Ntegeka, P. Willems, F. De Smedt, O. Batelaan, Hydrol. Process. 27, 3649 (2012)

29. R.E. Walpole, R.H. Myers, S.L. Myers, K. Ye, Probability and statistics for engineers and scientists (Prentice Hall, NJ 2002)

30. M. Wdowikowski, B. Kazimierczak, O. Ledwinka, Meteorol. Hydrol. Water Manag. 4-1, 53 (2016)

31. R.L. Wilby, Environ. Modell. Softw. 22, 1705 (2007)

32. D.S. Wilks, Clim. Change, 1, 898 (2010)

33. E. Zorita, H. von Storch, J. Climate, 12, 2474 (1999) 